\title{
HUMIC ACID CRACKING BY ACTIVATED CLAY CATALYSTS AND IDENTIFICATION OF ITS PRODUCTS
}

\author{
Abdullah $^{1}$, Rina Twinasty ${ }^{2}$ and Taufiqur Rohman ${ }^{3}$ \\ Department of Chemistry, Faculty of Mathematics and Natural Sciences, Lambung Mangkurat \\ University. Jl. A. Yani Km 35.8 South Kalimantan, Indonesia. Tel./Fax. +625114663375, \\ 1email: abdullah01@unlam.ac.id \\ ${ }^{2}$ Industrial Hygiene and Occupational Safety Office, Jl. Brigjen H. Hasan Basry no. 56 Banjarmasin, \\ 2email: rina_twinasty@yahoo.com
}

\begin{abstract}
Humic acid is a compound of colloidal, amorphous, and complex aromatic polymer with functional groups of - $\mathrm{COOH}$ (carboxyl), $\mathrm{OH}$ (phenol), and $\mathrm{C}=\mathrm{O}$ (carbonyl). The presence of these functional groups provides a rationale for assuming that humic acids have a potential to produce phenolic, carboxylic and carbonylic compounds through cracking process. In this study the cracking was done by isolating humic acids from peat soil, and facilitated by a clay catalyst which had been activated.

Humic acids were isolated by extracting the acids from the peat with $\mathrm{NaOH}$ and $\mathrm{HCl}$. The characterization of humic acids included the determination of the ash content by gravimetric method and the analysis of the functional groups of humic acids by Infrared spectrometer (FTIR). The clay to be activated was shaped into two forms, pellets and 20-40 mesh granules. The clay was activated by immersing it in $\mathrm{HCl}$ and $\mathrm{NH}_{4} \mathrm{NO}_{3}$, and then calcined. The characterization of catalysts included the determination of acidity and the $\mathrm{Si} / \mathrm{Al}$ ratio gravimetrically, as well as the analysis of the pore volume, maximum pore radius, surface area and average pore radius by Surface Area Analyzer NOVA-1000. Humic acid cracking was performed by a fixed-bed reactor system at a temperature of $400^{\circ} \mathrm{C}$. The Liquid smoke, the product of cracking, was analyzed by GC and GC-MS to determine the number of compounds and major compounds contained in the liquid smoke.

The results show that the isolated humic acid had ash content of $9.10 \%$. Activated clay had acidity and Si/Al ratio higher than the clay before actifated. Based on the analyses of GC and GC-MS it can be found out that the major compounds contained in liquid smoke, the product of humic acid cracking with 20-40 mesh catalyst
\end{abstract}

at a temperature of $400^{\circ} \mathrm{C}$ were phenolic compounds $(74.56 \%)$, and no carboxylic and carbonylic compounds as the major compounds. The activated clay can be used as the catalyst for humic acid cracking. cracking

Keywords: humic acid, catalyst, clay,

\section{INTRODUCTION}

In the macromolecular structure of humic acids, there are a wide variety of functional groups such as $-\mathrm{COOH}$ (carboxylic), $-\mathrm{OH}$ (phenolic), and $\mathrm{C}=\mathrm{O}$ (carbonyl). The presence of these functional groups is the rationale for assuming that humic acid mostly found in peat soils has a potential to become a source of chemicals like phenolic, carboxylic and carbonylic compounds. Such compounds can be obtained by cracking process. Cracking occurs when a fragment with a long chain is broken into carbons with a shorter chain (Campbell, 1988; Tanaka et al., 2001).

Cracking process usually needs acid catalyst to increase the rate of reaction (Nurjannah et al., 2010; Ardy et al., 2015). The cracking process can be aided by the presence of clay as the catalyst. The utilization of clay as the catalyst is based on the nature of its acidity, namely the presence of Bronsted and Lewis acid sites, and its surface area (Champbell, 1988). The ability of clay as a catalyst can be enhanced through a treatment called activation, and the result of clay activation is called the activated clay.

A previous study has shown that the pyrolysis of peat samples taken from Gambut District of South Kalimantan Province produced phenolic, carboxylic and carbonylic compounds (Abdullah and Herdiansyah, 2004). The contents of these compounds were still relatively low, $15.95 \%, 18.6 \%$, and $30.95 \%$ for phenol, carboxyl, and carbonyl 
(aldehyde and ketone), respectively. It was because there were many other components in addition to humic acid in the peat. Therefore, the isolation of humic acid from the peat is expected to produce aforementioned substantial chemical components with greater contents.

\section{MATERIALS AND METHODS}

The isolation of humic acid and the activation of clay were performed at the Primary Laboratory, Faculty of Mathematics and Natural Sciences, Lambung Mangkurat University in Banjarbaru. The analysis of $\mathrm{Si} / \mathrm{Al}$ ratio was conducted at the Laboratory of BARISTAN INDAG Banjarbaru, and the analysis of the average pore radius and surface area of clay at BATAN Banjarbaru. The analysis of chemical compounds of humic acid and liquid smoke was carried out at the Organic Chemistry Laboratory, Faculty of Mathematics and Natural Sciences, Gadjah Mada University.

\section{a. Equipment and Materials}

The equipment required in this study included oven, furnace, centrifuge, ashing cup, petri dish, condenser, stainless steel reactor, exicator, GC HEWLETT PACKARD 5890 SERIES II, GC-MS Shimadzhu QP5000, IR Shimadzhu FTIR-8201 PC, Sieve 20-40 mesh, Shaker GFL 3005, OHAUSS analytical balance, pH meter Jenway 3040 ion analyzer, Surface Area analyzer NOVA1000 , and glass tools.

The materials needed in the study were peat soil from Gambut District of South Kalimantan Province, red clay from Sungai Ulin, chemicals with quality p.a. $(\mathrm{NaOH}, \mathrm{HCl}$, buffers $\mathrm{pH} 4$ and $\mathrm{pH} 7, \mathrm{NH}_{4} \mathrm{NO}_{3}, \mathrm{NH}_{4} \mathrm{OH}$ ), glass wool and distilled water.

\section{b. Research procedures Humic acid isolation}

One hundred grams of peat soil was extracted with $1000 \mathrm{ml}$ of $0.1 \mathrm{M} \mathrm{NaOH}$ (soil/solvent ratio 1:10) for 24 hours. The supernatant was then poured in beaker glass and acidified with $6 \mathrm{M} \mathrm{HCl}$ to $\mathrm{pH} 1$ and let stand for 16 hours. After 16 hours, two layers were formed in the system; the top layer was fulvic acid (supernatant) and the base layer humic acid (precipitate). The supernatant (FA) and the precipitated (HA) were separated by centrifugation at $3,000 \mathrm{rpm}$ for 10 minutes. The solid residues were crude humic acids. The isolation was repeated until obtained 250 grams of humic acids. Furthermore, the humic acids were characterized by determining the ash content and the functional groups with Infrared spectrometer (FTIR-8201 Shimadzhu PC) in order to obtain humic acid functional groups.

\section{Clay activation}

Two hundred and fifty grams of clay was put into a beaker containing $750 \mathrm{ml}$ of $0.5 \mathrm{M} \mathrm{HCl}$, and shaked for 24 hours. The clay was then washed with distilled water until the $\mathrm{pH}$ of the washing water was the same as that of the clay. It was heated in a furnace at a temperature of $110^{\circ} \mathrm{C}$ for one hour, then at a temperature of $500^{\circ} \mathrm{C}$ for three hours, and coded LA-H. Furthermore, some of LA-H clay were given further treatments, exchanging ion with a $1 \mathrm{M}$ ammonium nitrate solution for 24 hours, heated at $350^{\circ} \mathrm{C}$ for three hours and labeled with the code $\mathrm{LA}-\mathrm{H}-\mathrm{NH}_{4}$. This activation process was for the clay sized 2040 mesh in the forms of pellets. The clay was characterized physically and chemically, including the determination of acidity, Si/Al ratio, surface area, pore volume, maximum pore radius and average pore radius. Clay with the code LA-H and clay with the code $\mathrm{LA}-\mathrm{H}-\mathrm{NH}_{4}$ were then used as the catalysts in cracking humic acid.

\section{Clay catalyst characterization}

The chemical analysis, determining acidity and $\mathrm{SI} / \mathrm{Al}$ ratio, was conducted using a gravimetric method while the physical analysis covering the determination of surface area, pore volume, average pore radius and maximum pore radius, using Surface Area Analyzer NOVA-1000.

\section{Humic acid cracking with clay catalyst}

The process of humid acid cracking is performed using a fixed-bed reactor system, which contained the catalyst and was made of stainless steel sized $10 \mathrm{~cm}$ long and 7.5 $\mathrm{cm}$ diameter. In principle, the reactor was divided into two rooms. The upper room was a place to put the catalyst (LA-H, and LA-H$\mathrm{NH}_{4}$ ), as much as two grams with the base of a glass wool. The lower part was for the humic acids as much as 20 grams.

Humic acids were heated in a furnace at $400^{\circ} \mathrm{C}$. The steam produced was taken out and the product (liquid smoke) was stored in an erlenmayer placed in a container containing ice and salt. Before performing catalytic cracking by clay catalysts, the humic 
acid cracking was performed without any acid catalyst at a temperature of $400^{\circ} \mathrm{C}$.

\section{Analysis of liquid smoke resulting from humic acid cracking \\ The liquid smoke was analyzed by GC} and GC-MS (at the Organic Chemistry Laboratory of Gadjah Mada University, Yogyakarta) to determine the number of compound components and the major compounds in the liquid smoke resulted from the cracking process.

\section{RESULTS AND DISCUSSION}

\section{Characteristics of Isolated Humic Acids}

Characterization of humic acids resulting from the isolation included ash content and identification of functional groups with IR. The ash content of the isolated humic acids was $9.10 \%$. IR spectra of the humic acids can be seen in Figure 1.

On the spectra, the $-\mathrm{OH}$ stretching vibration was identified in wavenumber $\left(\mathrm{cm}^{-1}\right)$ at $3425.3 \mathrm{~cm}^{-1}$, and the aliphatic $-\mathrm{CH}$ stretching vibration at $2920 \mathrm{~cm}^{-1}$ and 2850.6 $\mathrm{cm}^{-1}$. Absorption band appearing at 1716.5 $\mathrm{cm}^{-1}$ indicated $-\mathrm{C}=\mathrm{O}$ stretching vibration of the $-\mathrm{COOH}$ group. The absorption band at $1627.8 \mathrm{~cm}^{-1}$ was identified as $\mathrm{C}-\mathrm{C}=$ aromatic $\mathrm{C}-$ and $\mathrm{H}$ conjugated of ketone. $-\mathrm{OH}$ Stretching vibration of $-\mathrm{COOH}$ group and $\mathrm{CO}$ of $-\mathrm{COOH}$ group were identified at 1215.1 $\mathrm{cm}-1$. The absorption band was still visible on the infrared spectra at around $1380 \mathrm{~cm}-1$. This absorption arose because of the interaction of humic acids with metals (Aiken et al., 1985). It occurred because the humic acids obtained did not go through refining process that it had not been free of metals.

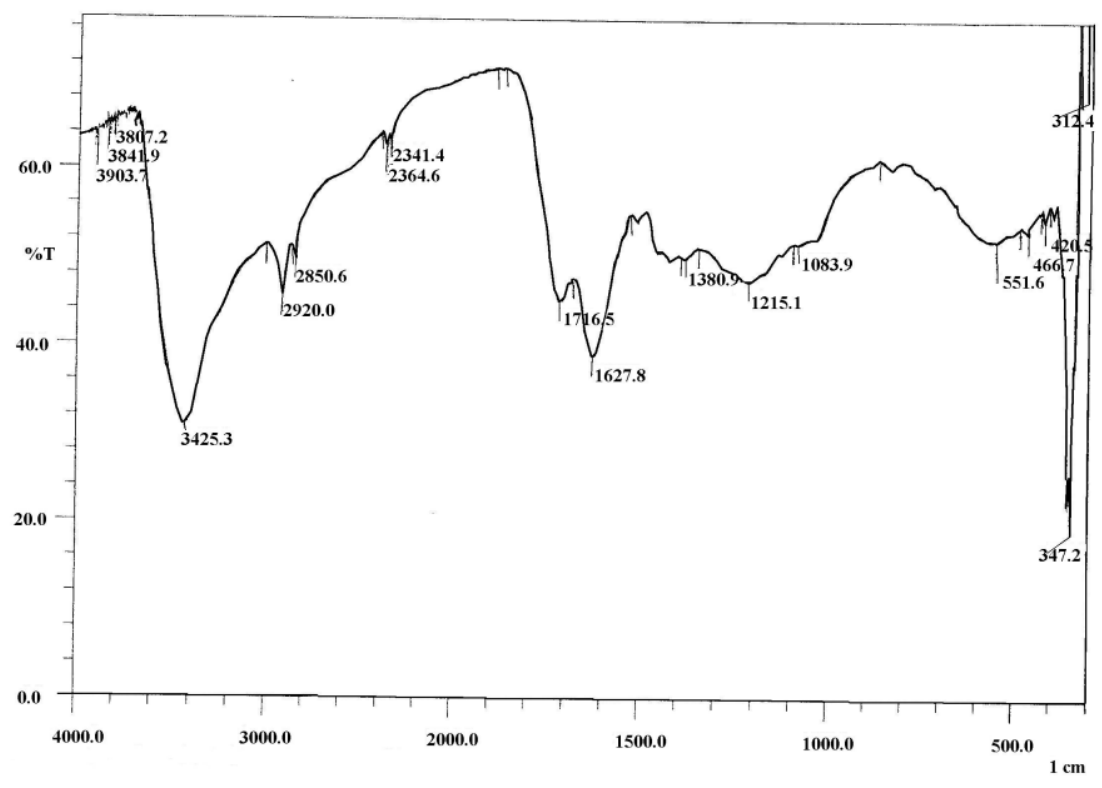

Figure 1. Infrared spectra of isolated humic acids

\section{Characteristics of Clay Catalyst}

Acid sites in the clay were determined gravimetrically. Total acidity of clay comes from Lewis acid site, derived from Al, and can also come from Bronsted acid site, namely $\mathrm{H}^{+}$. Consequently, the clay containing significant Al in its framework will have a greater site of Lewis acid. Likewise, the higher the content of $\mathrm{H}^{+}$, the greater the Bronsted acid site.

Total acidity measurement was based on the number of gas (vapor) of ammonia that adsorbed by clay surface equivalent to the amount of acid on clay surface absorbing as bases. In general, the acidity of the clay increased compared it before activated. From the calculation, the values of ammonia gas adsorption in clay pellets before activated, LA-H, and LA-H-NH ${ }_{4}$ were 0.0128; 0.0189; and 0.0264 , respectively. The values of ammonia gas adsorption in 20-40 mesh clay before activated, $\mathrm{LA}-\mathrm{H}$, and $\mathrm{LA}-\mathrm{H}-\mathrm{NH}_{4}$ were 0.0109 ; 0.0149 ; and 0.0250 , respectively. The increase in clay acidity before and after activation can be seen in Table 1 . 
Table 1 . Analysis results of total acidity of catalyst

\begin{tabular}{|c|c|c|}
\hline Shape & Sample & Total acidity $(\mathrm{mmol} / \mathrm{g})$ \\
\hline \multirow{3}{*}{ pellet } & Blank & 0.01285 \\
\hline & LA-H & 0.0189 \\
\hline & LA-H-NH & 0.02645 \\
\hline \multirow{3}{*}{$\begin{array}{l}\text { granule } \\
\text { (20-40 mesh) }\end{array}$} & Blank & 0.0109 \\
\hline & LA-H & 0.0149 \\
\hline & LA-H-NH ${ }_{4}$ & 0.0250 \\
\hline
\end{tabular}

Acid treatment caused the release of aluminum and other cations contained in the framework of clay because they were parts soluble in water, so washing of clay with distilled water washed out the impurity. Soaking the clay with ammonium nitrate caused ion exchange, the cations in active clay turning into ion $\mathrm{NH}_{4}{ }^{+}$. The next step was calcination for eliminating $\mathrm{NH}_{3}$, so that the $\mathrm{NH}_{4}{ }^{+}$ion bounded in the active clay turned into $\mathrm{H}^{+}$. These changes led formation of Bronsted acid group, which served to enhance the catalytic properties of clay. By release of $\mathrm{Al}$ from framework, it was expected that ratio of Si/Al would increase. $\mathrm{Si} / \mathrm{Al}$ ratio of clay in this study is given in Table 2. From the data was obtained, the $\mathrm{Si} / \mathrm{Al}$ ratio generally increased compared to the clay before activated.

Table 2. Results of Si/Al ratio analysis

\begin{tabular}{|c|c|c|}
\hline Shape & Sample & Si/Al Ratio \\
\hline \multirow{3}{*}{ pellet } & Blank & 2.67 \\
\hline & LA-H & 2.85 \\
\hline & $\mathrm{LA}-\mathrm{H}-\mathrm{NH}_{4}$ & 5.71 \\
\hline & Blank & 8.83 \\
\hline granule & $\mathrm{LA}-\mathrm{H}$ & 52.49 \\
\hline (20-40 mesh) & $\mathrm{LA}-\mathrm{H}-\mathrm{NH}_{4}$ & 76.50 \\
\hline
\end{tabular}

Dealumination with hydrochloric acid $(\mathrm{HCl})$ treatment and calcination made the framework Al turn out into the non-framework $\mathrm{Al}$ in the form of $\mathrm{AlCl}_{3}$ and $\mathrm{Al}(\mathrm{OH})_{3}$. $\mathrm{A}$ decrease of $\mathrm{Al}$ in the framework resulted increasing of $\mathrm{Si} / \mathrm{Al}$ ratio. The physical analysis included themeasurement of surface area, pore volume, maximum pore radius and average pore radius, all of which were analyzed using Surface Area Analyzer NOVA-1000. The characterization results are shown in Table 3.

Table 3. Results of Surface Area Analyzer analysis

\begin{tabular}{|c|c|c|c|c|c|}
\hline & Clay & $\begin{array}{c}\text { Surface area } \\
\left(\mathrm{m}^{2} / \mathrm{g}\right)\end{array}$ & $\begin{array}{l}\text { Maximum pore } \\
\text { radius }(\AA)\end{array}$ & $\begin{array}{l}\text { Total pore volume } \\
\quad \times 10^{-3}(\mathrm{cc} / \mathrm{g})\end{array}$ & $\begin{array}{l}\text { Average pore } \\
\text { radius }(\AA)\end{array}$ \\
\hline \multirow{3}{*}{ pellet } & Blank & 24.89 & 502.11 & 22.82 & 18.33 \\
\hline & LA-H & 24.14 & 591.44 & 23.15 & 19.17 \\
\hline & LA-H-NH ${ }_{4}$ & 25.21 & 880.90 & 22.91 & 18.17 \\
\hline \multirow{3}{*}{$\begin{array}{l}\text { granule } \\
\text { (20-40 } \\
\text { mesh) }\end{array}$} & Blank & 28.10 & 948.49 & 24.17 & 17.19 \\
\hline & LA-H & 21.00 & 991.79 & 15.48 & 14.74 \\
\hline & $\mathrm{LA}-\mathrm{H}-\mathrm{NH}_{4}$ & 21.77 & 1219.84 & 14.86 & 13.64 \\
\hline
\end{tabular}

For pellets, surface area of LA-H is smaller if compared to the blank, but increase for $\mathrm{LA}-\mathrm{H}-\mathrm{NH}_{4}$. For granule clay increase in the maximum pore radius occurred generally, but decrease in surface area for clay before activated.

The clay was activated in order to increase of its surface area. The clay with wider surface area was expected to have better adsorption capability, so that it could be used as a catalyst. However, the selection of a catalyst is not only on the basis of surface area, but also on the basis of other considerations such as acidity, mechanical stability and thermal stability. Activation through immersion of clay using chemical reagents and calcination, so crystallization of a catalyst become better and thermally more stable. Although there is clay that had not been activated and had a larger surface area, but based on mentioned considerations, for cracking of humic acids used the clay that had been activated as the catalyst.

\section{Humic Acid cracking with Clay Catalyst}


The cracking process of humic acids resulting from the isolation was carried out by a fixed-bed reactor system, consisting of two rooms. The lower room was for the humic acids and the upper room for the catalyst. The cracking was performed at a temperature of $400^{\circ} \mathrm{C}$. For comparison, the cracking process without a catalyst was also carried out at that same temperature. The product of the process in the form of gas was passed through the cooling system (ice-salt) and liquid products of the cracking were analyzed by GC and GC-MS to determine the number of compounds and major compounds contained in liquid smoke.

It can be seen in Figure 2 that the products of the cracking using $\mathrm{LA}-\mathrm{H}$ pellet catalyst shows the increase in the number of components when compared to the compounds from the cracking process without a catalyst, which was characterized by increase in the number of peak of liquid smoke chromatogram from 23 to 32 peaks.

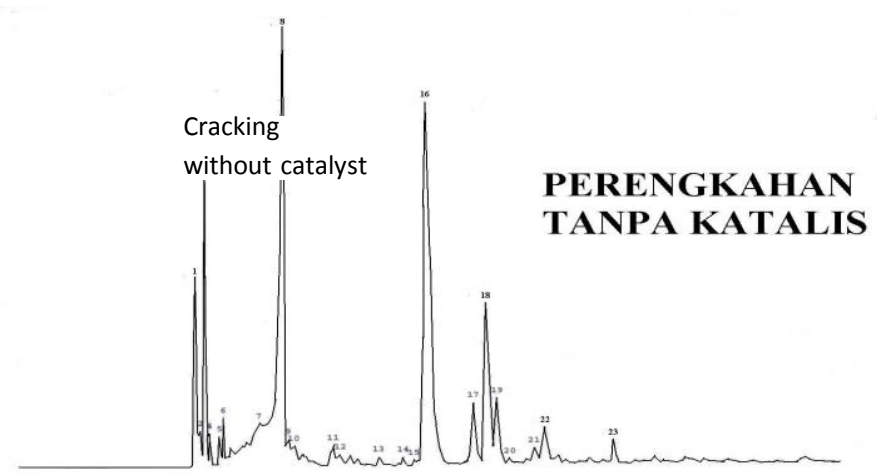

Figure 2. GC chromatogram of humic acids cracked without catalyst

In Figure 3 we can see the liquid smoke chromatogram of humic acids cracked with $\mathrm{LA}-\mathrm{H}-\mathrm{NH}_{4}$ catalyst. Based on these images, there were an increasing number of peaks in the chromatogram, from 23 to 31 peaks. Despite a decline in activity of $\mathrm{H}-\mathrm{NH}_{4}$

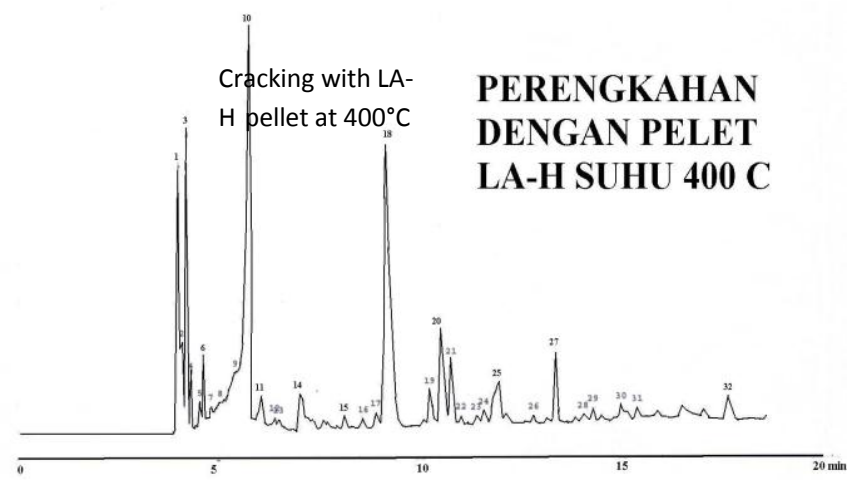

Figure 3. GC chromatogram of humic acids cracked with LA-H pellet catalyst

Chromatogram of liquid smoke resulting from humic acid cracking with 20-40 catalyst, which only produced 31 peaks, compared with LA-H catalyst producing 32 peaks, at the retention time of 0 to 10 minutes the cracking process with LA-H only produced 18 peaks while with $\mathrm{LA}-\mathrm{H}-\mathrm{NH}_{4}$ generated 23 peaks.

PERENGKAHAN

LA-H SUHU $400 \mathrm{C}$

mesh catalyst can be seen in Figure $4(\mathrm{LA}-\mathrm{H})$ and Figure $5\left(\mathrm{LA}-\mathrm{H}-\mathrm{NH}_{4}\right)$. 


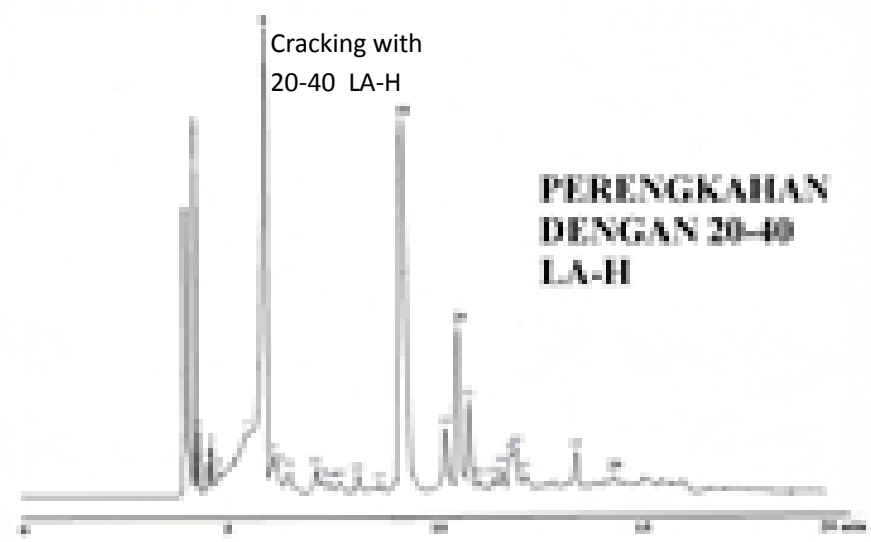

Figure 4. GC chromotogram of humic acids cracked with LA-H catalyst (20-40 mesh granules)

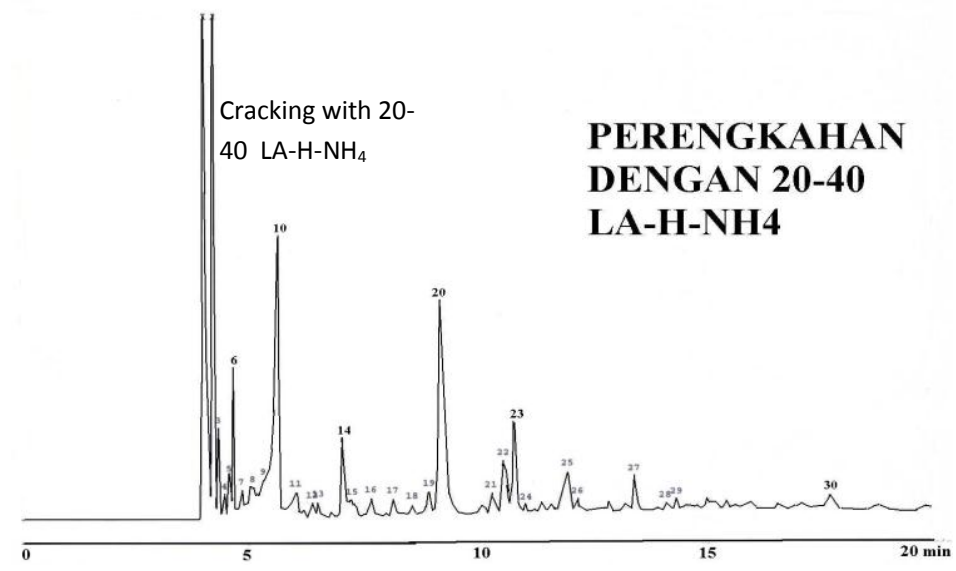

Figure 5. GC chromatogram of humic acids cracked with $\mathrm{LA}-\mathrm{H}-\mathrm{NH}_{4}$ catalyst (20-40 mesh granules)

It can be seen from both figures that the cracking process with catalysts gave better results, as compared to the cracking without a catalyst. It is indicated by the growing number of chromatogram peaks from 23 to 29 and to 30 peaks. In general, the activity of $\mathrm{LA}-\mathrm{H}-\mathrm{NH}_{4}$ catalyst was better than LA-H catalyst because of its higher acidity. Acidity is identical to active site in the process of cracking.

\section{Analysis of Lead Chemical Compounds in Liquid Smoke}

Major compounds in liquid products resulting from the cracking were determined by GC-MS method. MS spectra will translate the peaks produced by GC to indicate the relative mass of the molecule and the relative mass of its fraction. If it is seen from the GC chromatogram pattern, from each liquid smoke product resulting from humic acid cracking with various clay catalysts it can be inferred that the major compounds were the same. The results of GC-MS analysis of liquid smoke from humic acid cracking at a temperature of $400^{\circ} \mathrm{C}$ with $20-40$ mesh catalysts, in estimating the compounds contained in the liquid smoke, can be seen in Figure 6. Based on the results of GC-MS analysis, the expected compounds contained in the liquid smoke were phenol, 2metilphenol, 3-metilphenol, 4-etilphenol, and 1,2-benzenadiol. Viewed from the groups possessed by these compounds, the major compounds of liquid smoke were dominated by phenolic compounds.

A study on peat pyrolysis by Abdullah (2004), estimated that in the liquid smoke resulting from peat pyrolysis contained $15.95 \%$ phenolic compound; $18.60 \%$ carboxylic compound; and $30.95 \%$ carbonyl compound as major compounds. In the study, peat samples were taken from various different depths, namely the surface peat, peat taken from a depth of half a meter and peat from a depth of two meters. The similarity found in the study on humic acid cracking and that study on peat pyrolysis was that the peat samples were taken from the same area. The peat samples that met the criteria were taken from the surface and from 
the depth of half a meter, so the peat samples from the depth of two meters were ignored. Through the process of humic acid cracking, it is also alleged that the humic acid cracking can produce compounds mentioned above because humic acid has functional groups, such as $-\mathrm{OH},-\mathrm{COOH}$ and $\mathrm{C}=\mathrm{O}$ in its structure.
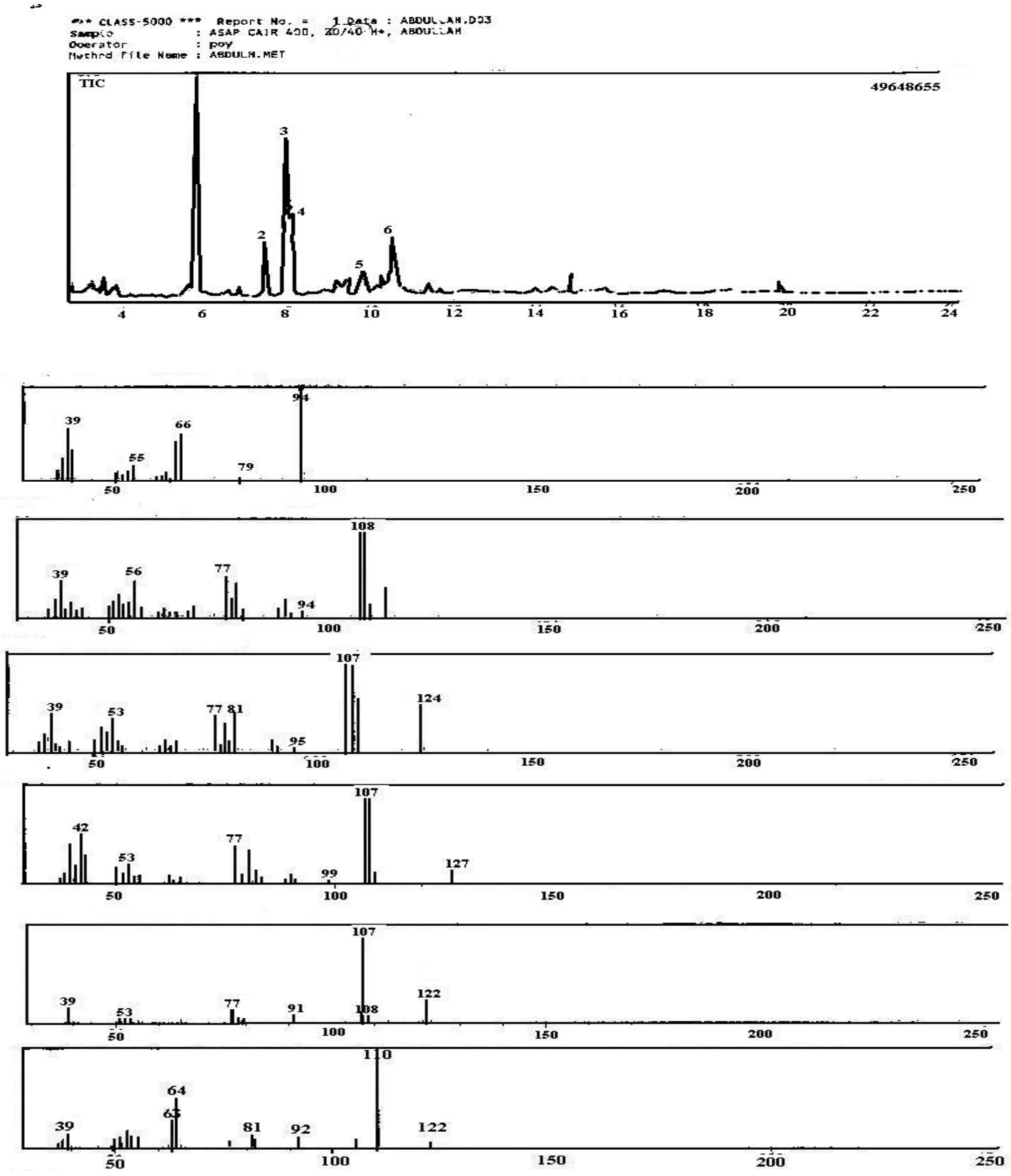

Figure 6. Results of GC-MS of liquid smoke from humic acid cracking with 20-40 mesh LA-H catalyst at a temperature of $400^{\circ} \mathrm{C}$ 
The result of the study by Abdullah and Herdiansyah (2004) can be used as a reference to find out whether or not the humic acid cracking can produce higher concentration of phenol, carbonyl, and carboxyl. Results of GC and GC-MS analyses of liquid smoke of humic acids from cracking process at a temperature of $400^{\circ} \mathrm{C}$ (with 20-40 mesh LA-H catalyst) indicate that $74.56 \%$ of the compounds present in the liquid smoke were phenolic compounds. The percentage of major compounds produced in the processes of peat pyrolysis and humic acid cracking can be seen in Table 4 .

Table 4. Concentration of major compounds resulting from peat pyrolysis and humic acid cracking

\begin{tabular}{ccc}
\hline Major compounds & Peat pyrolysis $^{\text {a }}$ & Humic acid cracking \\
\hline Carboxyl & $18.60 \%$ & - \\
\hline Carbonyl & $30.95 \%$ & - \\
\hline Phenol & $15.95 \%$ & $74.56 \%$ \\
\hline : Data from Abdullah and Herdiansyah (2004) & &
\end{tabular}

Based on the data in the table, it can be inferred that humic acid cracking produced phenolic compounds with greater concentration. The major compounds of carboxyl and carbonyl were not found in the products of humic acid cracking process, but they were likely in small concentrations.

\section{CONCLUSIONS}

It can be concluded from the results of humic acid cracking with clay catalysts that:

1. Humic acids resulting from isolation are crude humic acids with the ash content of $9.10 \%$.

2. Activation of clay by immersion with $\mathrm{HCl}$, $\mathrm{NH}_{4} \mathrm{NO}_{3}$ and calcination can increase the acidity and the Si/Al ratio of clay.

3. Activated clay can be used as the catalyst for humic acid cracking, but the major compounds produced are nearly the same as those produced in the cracking process without a catalyst.

4. Major compounds of liquid smoke resulting from humic acid cracking with clay catalysts are phenol, 2-metilphenol, 3-metilphenol, 4-etilphenol, and 1,2benzenadiol, all of which are phenolic compounds.

5. Humic acid cracking with 20-40 mesh LA$\mathrm{H}$ catalyst at a temperature of $400^{\circ} \mathrm{C}$ can produce phenolic compounds as the major compounds with a concentration of $74.56 \%$ (greater than those produced by peat pyrolysis, only $15.95 \%$ ), but the carbonylic and carboxylic compounds are not the major compounds.

\section{REFERENCES}

Abdullah and Herdiansyah, 2004. Peat Pyrolysis and Catalytic Conversion of Its Product, Liquid Smoke (Biofuel), into Chemical Compounds of Petroleum fractions. Research Report, Faculty of Mathematics and Natural Science, Lambung Mangkurat University, Banjarmasin. Page 30-35.

Aiken, G.R, D.M. McKnight, R.L Wershaw, and P.Mac Carthy, 1985. Humic Substance in Soil, Sedimen and Water: Geochemistry, Isolation and Charactrization. John Wiley \& Son, New York. Hal 19, 23-24, 545.

Ardy A., Susanto H., and Subagjo, 2015. Laboratory Test of Toluene Cracking Process with Catalyst of Steamed Reform Ni / a-Al2O3, Proceedings of the National Seminar on Chemical Engineering "Kejuangan" ISSN 1693-4393. Chemical Engineering ITB, Bandung.

Champbell, I. M, 1988. Catalysis at Surface, First edition, Chapman and Hall, New York. Page 8.

Nurjannah, Achmad R. and Prajitno D.H., 2010. Catalytic Conversion of Palm Oil to Produce Biofuel Using Silica Alumina and HZMSM-5 Synthesis. Reactor, Vol. 13 No. 1, June 2010, Page: 37-43.

Schnitzer, 1995. Interaction of Soil Mineral and Natural Organism and Microbe. UGM Press, Yogyakarta. Page 121-122.

SaputroH. S., 1993. Manufacture of Nickel Hydrogenation Catalysts with clay 
Abdullah, Rina Twinasty and Taufiqur Rohman: Humic Acid Cracking By Activated Clay Catalysts

as Supporting Material. Thesis,

Graduare School UGM.

Yogyakarta, Page 28-29.

Tan, K.H, 1995. Fundamentals in Soil Chemistry. Gadjah Mada University Press, Yogyakarta. Page 55-58, 93102.

Tanaka T., Nagao S. and Ogawa H., 2001. Attenuated Total Reflection Fourier Transform Infrared (ATR-FTIR) Spectroscopy of Functional Groups of Humic Acid Dissolving in Aqueous Solution, Proceedings of IUPAC International Congress on Analytical Sciences. Page 10811084.

Wijaya, et al., 2004. Synthesis of Iron OxideMonmorillonite Composite and Study of Its Struktural Stabilyty Againts Sulfuric Acid, Indonesian Journal of Chemistry Volume 4(1):33-42. 